\title{
Comparison of the functional and cardiovascular effects of home-based versus supervised hospital circuit training exercises in male wheelchair users with chronic paraplegia
}

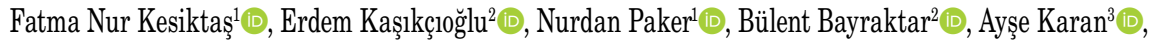 \\ Ayşegül Ketenci ${ }^{3}$ (D) Lütfiye Müslümanoğlu (D) \\ ${ }^{1}$ Department of Physical Medicine and Rehabilitation, Istanbul Physical Therapy Rehabilitation Training and Research Hospital, Istanbul, Turkey \\ ${ }^{2}$ Istanbul Faculty of Medicine, Sports Medicine, Istanbul, Turkey \\ ${ }^{3}$ Department of Physical Medicine and Rehabilitation, Istanbul University Istanbul Faculty of Medicine, Istanbul, Turkey
}

Received: May 08, 2020 Accepted: December 14, 2020 Published online: September 01, 2021

\begin{abstract}
Objectives: The aim of this study was to compare the efficacy of home-based upper extremity circuit training exercises (CTEs) with supervised hospital program in male patients with traumatic complete paraplegia.

Patients and methods: Twenty men with paraplegia (mean age: $38 \pm 10.1$ years; range, 30 to 43 years) between January 2007 and November 2007 were randomized into two groups. The first group had supervised hospital CTE program, whereas the second group had home-based CTE. The effects of the upper extremity CTE by using elastic bands $60 \mathrm{~min}$ per day, five days a week, for a total of eight weeks (70\% maximal oxygen consumption $\left[\mathrm{VO}_{2} \mathrm{max}\right]$ ) were examined. The Cybex was used for the isokinetic testing of the upper extremities. $\mathrm{The}^{\mathrm{VO}} \mathrm{max}_{2}$ and maximum heart rate (HR) were assessed using an arm ergometer. The Craig Handicap Report Technique Short Form (CHART-SF) was used for the evaluation of functional independence and mobility. Serum lipid profiles were measured.

Results: The mean injury duration was $7.9 \pm 2$ years. The peak torque values of the upper extremities, $\mathrm{VO}_{2}$ max, maximum HR, CHART-SF physical independence and mobility scores, and serum lipid profile were all improved in both groups $(\mathrm{p}<0.05)$. There were no significant differences in terms of the increase in the muscle strength and serum lipid levels between the groups ( $>0.05)$. The improvement in the $\mathrm{VO}_{2} \mathrm{max}$, physical independence, and mobility scores were greater in the supervised exercise group.

Conclusion: Upper extremity strength, cardiovascular endurance, and lipid profile were improved after supervised and home-based CTE in the men with paraplegia. Home-based exercise programs may be good alternatives to the hospital rehabilitation for this patient population.

Keywords: Exercise, male, maximal oxygen consumption, paraplegia, spinal cord injury, upper extremity, wheelchair.
\end{abstract}

Individuals with spinal cord injury (SCI) have usually rehabilitation in the hospital setting in the acute phase. After discharge, most of them have a sedentary life style. Moderate-to-vigorous exercise levels are low among the wheelchair user individuals with chronic paraplegia. ${ }^{[1]}$ Cardiovascular endurance and muscle strength tend to usually decrease by time after SCI. Physical activity usually decreases and metabolism changes. ${ }^{[2]}$ Patients with SCI can be dependent in specific tasks due to not being physically fit. Low functional capacity may lead to the restriction of mobility and independence and eventually may cause to increased cardiovascular (CV) risk. ${ }^{[3]}$ Therefore, long-term complications are relatively common in SCI. ${ }^{[4,5]}$ Rehabilitation helps to increase physical capacity. ${ }^{[6]}$ Aerobic exercises combined with muscle strength training have positive effects on the physical fitness, muscle strength, and

Corresponding author: Fatma Nur Kesiktaş, MD. İstanbul Fizik Tedavi Rehabilitasyon Eŭitim ve Araştırma Hastanesi, Fiziksel Tıp ve Rehabilitasyon Kliniği, 34186 Bahçelievler, İstanbul, Türkiye. e-mail: nur.kesiktas@gmail.com 
functional status. ${ }^{[7]}$ In particular, the upper extremity rehabilitation can protect the individual with paraplegia against the metabolic conditions over time. ${ }^{[8]}$

Circuit training exercises (CTEs) help to improve upper extremity muscle strength and endurance in SCI. ${ }^{[9-13]}$ There are limited studies in SCI patients with elastic bands. ${ }^{[9,14]}$ The elastic bands are used for CTE, as they are inexpensive and easy-to-use. Moreover, home-based circuit resistance training is safe and useful for the increase in muscle strength, besides the improvement in the CV endurance. ${ }^{[1]}$ Home programs are economically good alternatives to the rehabilitation programs in the hospital setting. In the present study, we aimed to compare the effects of the home-based and supervised hospital CTEs on the functional status and $\mathrm{CV}$ endurance in male wheelchair users with chronic paraplegia.

\section{PATIENTS AND METHODS}

This prospective, randomized study was conducted at Istanbul Physical Therapy Rehabilitation Training and Research Hospital, Department of Physical Medicine and Rehabilitation, between January 2007 and November 2007. A total of 68 men with paraplegia who met the study criteria were screened. Inclusion criteria were age between 18 and 55 years, having a lesion level between the $4^{\text {th }}-12^{\text {th }}$ thoracic vertebrae, having a complete injury as assessed by the American Spinal Injury Association Impairment Scale (AIS) and using a wheelchair. Patients over 55 years were not subjected for the study, due to maximal oxygen consumption $\left(\mathrm{VO}_{2 \max }\right)$ decreases by aging. Only male patients were included in this study due to anatomophysiological differences and $\mathrm{VO}_{2 \max }$ is 15 to $30 \%$ higher in men than women. The patients whose the injury level was higher than the $4^{\text {th }}$ thoracic vertebrae were not subjected for the study due to the autonomic dysfunction risk. Those who did not attend to at least four exercise sessions (10\%) during the study were also excluded. Finally, 20 men (mean age: $38 \pm 10.1$ years; range, 30 to 43 years) with complete chronic traumatic SCI according to sample size estimation and budget of trial among 68 eligible SCI were included. The CONSORT diagram of the study is shown in Figure 1. A written informed consent was obtained from the study. The study protocol was approved by the Ethics Committee of Istanbul University, Istanbul Faculty of Medicine (No: 2005/847). The study was conducted in accordance with the principles of the Declaration of Helsinki.

Neurological status was determined according to the AIS. On physical examination, there was no

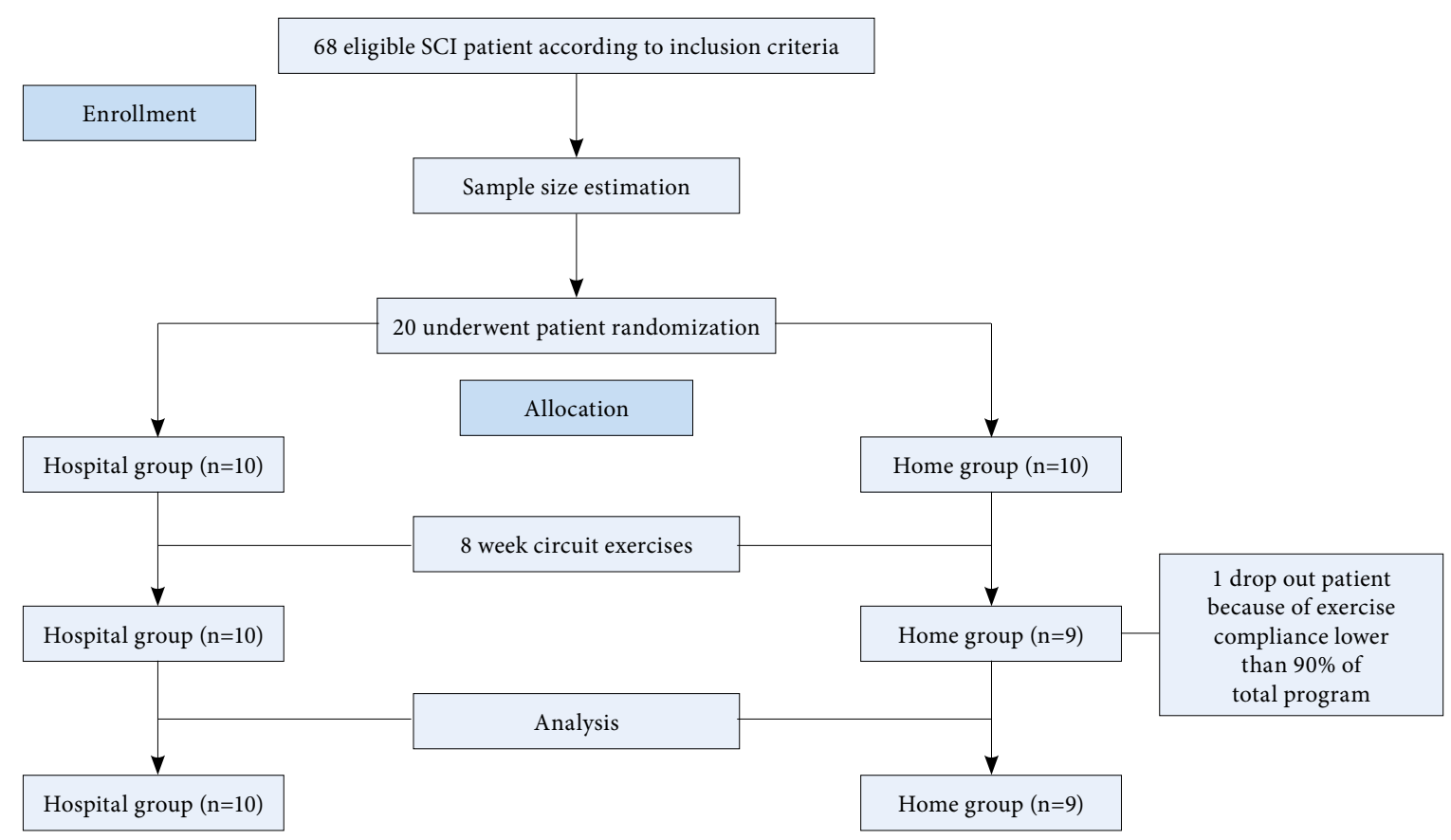

Figure 1. CONSORT diagram of the study.

SCI: Spinal cord injury. 
restriction in the shoulder range of motion. All patients had cardiac examination before doing exercises. Blood samples for lipids were obtained at baseline and after end of the treatment.

All patients were randomized into two groups with a computer program GraphPad-Quickcalcs (GraphPad Software, San Diego, CA, USA) in which designed for one-day workshop at baseline. The first group had supervised CTE in the hospital setting under the control of the same physician. The second group had a home-based CTE program. A special booklet including a general information about the disease was given to all patients. All patients in the home group had a three-day training program in the hospital at baseline. Printed documents containing CTEs were given to the home group and they were followed strictly by the weekly phone calls. All patients were evaluated at baseline and at the end of eight weeks.

\section{Circuit training exercise}

The CTE program was consisted of upper extremity stretching and strengthening with elastic bands (Rehband Anatomiska AB, Sollentuna, Sweden). Green and blue elastic bands were used for medium and heavy resistance, respectively. Every exercise session was continued for $1 \mathrm{~h}$. Supervised and home CTEs were five days a week for eight-week. Shoulder external and internal rotators, adductors, abductors, flexors, and latissimus dorsi as shoulder girdle depressor muscles were included in strengthening program. Pectoralis major, shoulder internal rotators, and biceps muscles were included in the stretching program. The wheelchair CTE program was built with $70 \%$ of heart rate (HR) in $\mathrm{VO}_{2 \max }, \mathrm{F} 1 /$ F2 Polar Heart Rate Monitor (Polar Electro Oy, Kempele, Finland), and HR monitors were given to both groups. All patients had medium-pressure surgical stockings (12-20 mmHg Mediven ${ }^{\circ}$ Varicose Stockings, NC, USA) during the exercise program to prevent peripheral ponding. The measurements were done at baseline and at the end of eight weeks.

\section{Measurement tools}

\section{Isokinetic measurement}

Both bilateral shoulder and elbow flexion and extension peak torque values were measured using the Cybex-Humac Norm isokinetic dynamometer (Lumex, Ronkonkoma, NY, USA). Lower parts of the body were stabilized by velcro straps and the shoulder was positioned at $45^{\circ}$ abduction. Three trials were performed at four-speed levels. The Cybex manual tests were measured at $60 \% \mathrm{sec}$ in supine position.

\section{Exercise stress test}

The Medisoft Stress electrocardiography test (MediSoft S.A. Dinant, Belgium) equipment was used to evaluate the heart functions. For measuring the CV load, a multi-step exercise test protocol was performed with an arm ergometer (917,900 M; Lode BV, Groningen, Netherlands). The exercise test protocol continued until the patient became exhausted with an arm ergometer $6 \mathrm{~min}$ in a wheelchair, followed by rest period, resistant (0W) period of 2 min warming, then the load was increased by $10 \mathrm{~W}$ every $2 \mathrm{~min}$. Metabolic measurement test was made using the Cortex Metalyzer $^{\circledast} \mathrm{D}$ ergospirometry at the same time during the stress test. The $\mathrm{VO}_{2 \max }$ was measured using the breath-by-breath method zirconium oxide, carbon monoxide in expiratory air was measured by an infrared analyzer using the 2900/C Sensor Medics (Sensor Medics Vmax29 system, CA, USA) and was performed with the help of a metabolic gas measurement device.

\section{Craig Handicap Assessment and Reporting Technique Short Form (CHART-SF)}

The CHART-SF is used to evaluate disabilityrelated physical and cognitive impairments. ${ }^{[15,16]}$ It is an easy test which can be completed by face-to-face interviews or as a self-administered test. It has six domains, as physical independence, cognitive independence, mobility, occupation, social integration, and economic self-sufficiency. The highest domain score is 100 . Higher scores indicate that the individual does specific tasks better.

\section{Statistical analysis}

Statistical analysis was performed using the SPSS version 10.0 software (SPSS Inc., Chicago, IL, USA). Sample size was calculated taking into account results of means and standard deviations (SDs) of pre- and post-treatment maximum HR values as described previously. ${ }^{[17]}$ Minimum sample size was estimated as nine (two-sided, $\alpha=0.05$, $1-\beta=0.8)$. Continuous data were presented in mean $\pm \mathrm{SD}$ and median (interquartile range [IQR]), while categorical data were presented in number and frequency. Group differences were compared using the Mann-Whitney $U$ test. The Wilcoxon test was used in the analysis of quantitative dependent data. The Fisher's exact test was used to compare qualitative data. A $p$ value of $<0.05$ was considered statistically significant. 


\begin{tabular}{|c|c|c|c|c|c|c|c|c|c|}
\hline \multicolumn{10}{|c|}{$\begin{array}{c}\text { TABLE } 1 \\
\text { Demographic and clinical characteristics of patients }\end{array}$} \\
\hline & \multicolumn{4}{|c|}{ Hospital group $(\mathrm{n}=10)$} & \multicolumn{4}{|c|}{ Home group $(\mathrm{n}=10)$} & \multirow[b]{2}{*}{$p$} \\
\hline & $\mathrm{n}$ & $\%$ & Median & IQR & $\mathrm{n}$ & $\%$ & Median & IQR & \\
\hline Age (year) & & & 35 & $30-43$ & & & 36 & $32-41$ & $\mathrm{U}=34 ; \mathrm{p}=0.223$ \\
\hline SCI duration (year) & & & 8 & $7-9.2$ & & & 7.8 & $7-9.3$ & $\mathrm{U}=49.5 ; \mathrm{p}=0.968$ \\
\hline Height $(\mathrm{cm})$ & & & 170 & $1.65-180$ & & & 175 & $169-181$ & $\mathrm{U}=35 ; \mathrm{p}=0.250$ \\
\hline Weight (kg) & & & 70 & $68-80$ & & & 68.5 & $66.5-81$ & $\mathrm{U}=45 ; \mathrm{p}=0.729$ \\
\hline Married & 5 & 50 & & & 5 & 50 & & & $\chi^{2}=0 ; p=1$ \\
\hline Levels T4-6 & 3 & 30 & & & 2 & 20 & & & $\chi^{2}=0.2 ; p=0.905$ \\
\hline T7-9 & 3 & 30 & & & 4 & 40 & & & \\
\hline T10-12 & 4 & 40 & & & 4 & 40 & & & \\
\hline
\end{tabular}

\section{RESULTS}

The mean injury duration was $7.9 \pm 2$ (range, 7 to 9.3) years. Demographic and clinical characteristics of the patients are shown in Table 1. Bilateral shoulder flexion and extension and elbow flexion and extension peak torque showed a statistically significant increase in both groups $(p<0.05)$. There were no statistically significantly differences in terms of the changes in the muscle test results between the groups (Table 2).
The $\mathrm{VO}_{2 \max }$ and $\mathrm{HR}$ were improved statistically significantly in both groups (Table 3$) \quad(\mathrm{p}<0.05)$. However, the increase in $\mathrm{VO}_{2 \max }$ was statistically significantly higher in the supervised CTE group than the home-based CTE group ( $\mathrm{p}<0.05)$.

The functional independence and mobility scores of the CHART-SF were improved significantly in the supervised CTE group $(\mathrm{p}<0.05)$, while the improvement in the home CTE group was not statistically significant

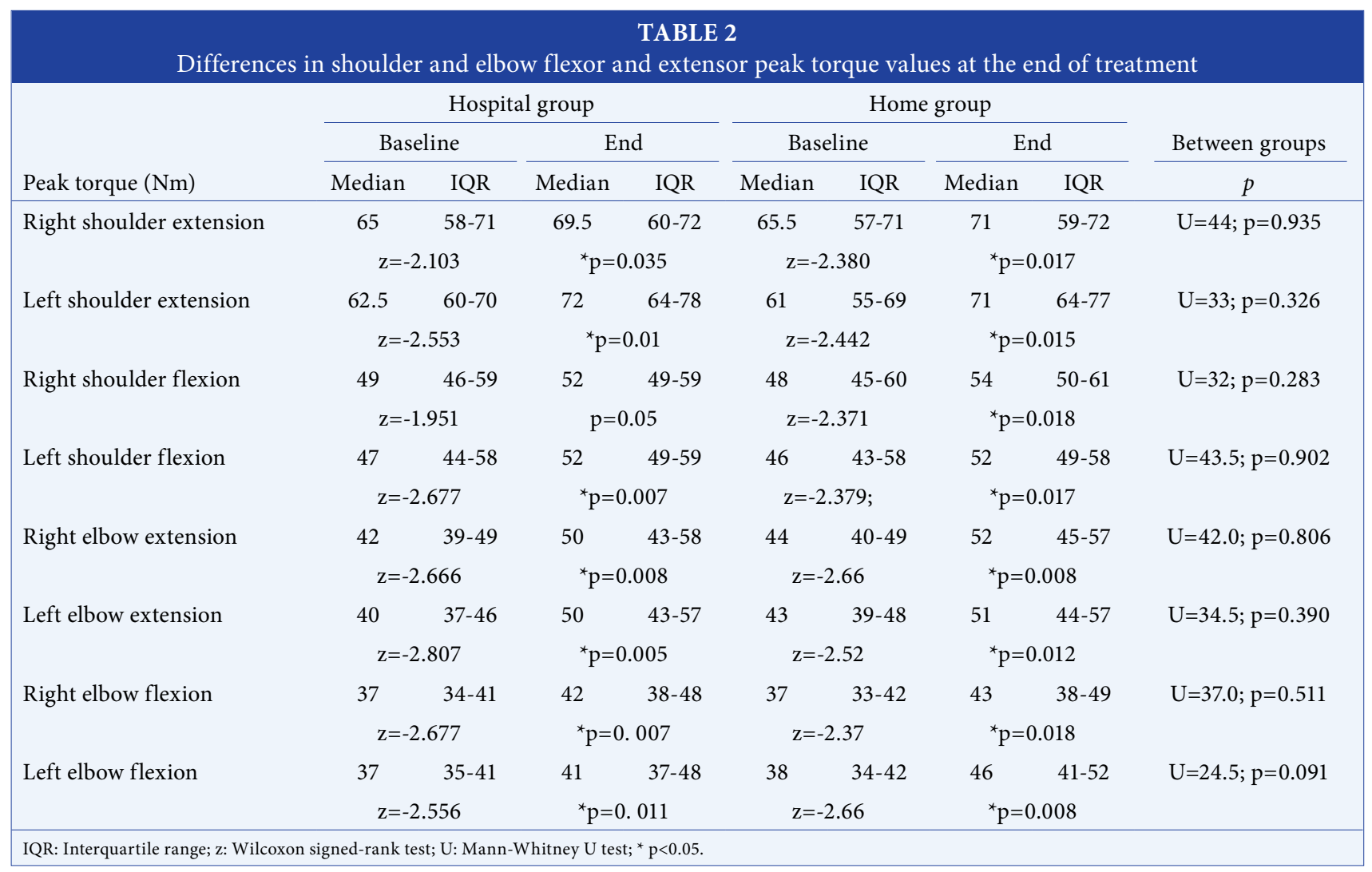




\begin{tabular}{|c|c|c|c|c|c|c|c|c|c|}
\hline & ifference & in $\mathrm{VO}_{2} \mathrm{~m}$ & ax and $\mathrm{m}$ & $\begin{array}{l}\text { TABLE } \\
\text { aximum }\end{array}$ & 3 & at the enc & of treatm & ent & \\
\hline & \multicolumn{4}{|c|}{ Hospital group } & \multicolumn{4}{|c|}{ Home group } & \multirow{3}{*}{$\begin{array}{c}\text { Between groups } \\
p\end{array}$} \\
\hline & \multicolumn{2}{|c|}{ Baseline } & \multicolumn{2}{|c|}{ End } & \multicolumn{2}{|c|}{ Baseline } & \multicolumn{2}{|c|}{ End } & \\
\hline & Median & IQR & Median & IQR & Median & IQR & Median & IQR & \\
\hline \multirow[t]{2}{*}{$\mathrm{VO}_{2} \max (\mathrm{mL} / \mathrm{kg} / \mathrm{min})$} & 16.5 & $15-19$ & 24 & $21-27$ & 15.5 & $14-17.5$ & 19 & $17-22$ & $\mathrm{U}=14.5 ;{ }^{* *} \mathrm{p}=0.012$ \\
\hline & \multicolumn{2}{|c|}{$\mathrm{z}=2.814$} & \multicolumn{2}{|c|}{${ }^{*} \mathrm{p}=0.005$} & \multicolumn{2}{|c|}{$\mathrm{z}=2.499$} & \multicolumn{2}{|c|}{${ }^{*} \mathrm{p}=0.012$} & \\
\hline \multirow[t]{2}{*}{ Max HR (beat/min) } & 173 & $164-185$ & 150.5 & $145-163$ & 167 & $162-180$ & 145 & $140-152$ & $\mathrm{U}=30 ; \mathrm{p}=0.220$ \\
\hline & \multicolumn{2}{|c|}{$\mathrm{z}=2.807$} & \multicolumn{2}{|c|}{${ }^{*} \mathrm{p}=0.005$} & \multicolumn{2}{|c|}{$\mathrm{z}=2.192$} & \multicolumn{2}{|c|}{${ }^{*} \mathrm{p}=0.028$} & \\
\hline
\end{tabular}

\begin{tabular}{|c|c|c|c|c|c|c|c|c|c|}
\hline \multirow[b]{4}{*}{ CHART SF domains } & \multicolumn{8}{|c|}{$\begin{array}{c}\text { TABLE } 4 \\
\text { Differences in CHART-SF at the end of treatment }\end{array}$} & \multirow{4}{*}{$\begin{array}{c}\text { Between groups } \\
p\end{array}$} \\
\hline & \multicolumn{4}{|c|}{ Hospital group } & \multicolumn{4}{|c|}{ Home group } & \\
\hline & \multicolumn{2}{|c|}{ Baseline } & \multicolumn{2}{|c|}{ End } & \multicolumn{2}{|c|}{ Baseline } & \multicolumn{2}{|c|}{ End } & \\
\hline & Median & IQR & Median & IQR & Median & IQR & Median & IQR & \\
\hline \multirow[t]{2}{*}{ Independence } & 47 & $40-58$ & 57 & $50-67$ & 64 & $54-73$ & 67 & $59-76$ & $\mathrm{U}=20.5 ;{ }^{* *} \mathrm{p}=0.039$ \\
\hline & \multicolumn{2}{|c|}{$\mathrm{z}=2.53$} & \multicolumn{2}{|c|}{${ }^{*} \mathrm{p}=0.011$} & \multicolumn{2}{|c|}{$\mathrm{z}=1.84$} & \multicolumn{2}{|c|}{$p=0.06$} & \\
\hline \multirow[t]{2}{*}{ Function in society } & 47 & $37-58$ & 51 & $44-60$ & 51 & $42-58$ & 54 & $43-61$ & $\mathrm{U}=38 ; \mathrm{p}=0.545$ \\
\hline & \multicolumn{2}{|c|}{$\mathrm{z}=2.232$} & \multicolumn{2}{|c|}{${ }^{*} \mathrm{p}=0.026$} & \multicolumn{2}{|c|}{$\mathrm{Z}=1.84$} & \multicolumn{2}{|c|}{$\mathrm{p}=0.06$} & \\
\hline \multirow[t]{2}{*}{ Mobility } & 46 & $38-54$ & 54 & $44-63$ & 56 & $47-63$ & 58 & $50-66$ & $\mathrm{U}=16 ;{ }^{* *} \mathrm{p}=0.016$ \\
\hline & \multicolumn{2}{|c|}{$\mathrm{z}=2.03$} & \multicolumn{2}{|c|}{${ }^{*} \mathrm{p}=0.04$} & \multicolumn{2}{|c|}{$\mathrm{z}=1.84$} & \multicolumn{2}{|c|}{$\mathrm{p}=0.06$} & \\
\hline \multirow[t]{2}{*}{ Ability to work } & 33 & $23-44$ & 36 & $23-48$ & 40 & $31-48$ & 42 & $31-49$ & $\mathrm{U}=34 ; \mathrm{p}=0.337$ \\
\hline & \multicolumn{2}{|c|}{$\mathrm{z}=2.242$} & \multicolumn{2}{|c|}{${ }^{*} \mathrm{p}=0.025$} & \multicolumn{2}{|c|}{$\mathrm{z}=1.604$} & \multicolumn{2}{|c|}{$\mathrm{p}=1.09$} & \\
\hline \multirow[t]{2}{*}{ Socialize } & 77 & $70-85$ & 79 & $70-86$ & 83 & $79-89$ & 83 & $79-89$ & $\mathrm{U}=36 ; \mathrm{p}=0.168$ \\
\hline & \multicolumn{2}{|c|}{$\mathrm{z}=1.34$} & \multicolumn{2}{|c|}{$\mathrm{p}=0.18$} & \multicolumn{2}{|c|}{$\mathrm{z}=0.00$} & \multicolumn{2}{|c|}{$\mathrm{p}=1$} & \\
\hline
\end{tabular}

\begin{tabular}{|c|c|c|c|c|c|c|c|c|c|}
\hline \multirow[b]{4}{*}{ Lipids (mg/dL) } & \multicolumn{8}{|c|}{$\begin{array}{l}\text { TABLE } 5 \\
\text { rences in serum lipid profile at the er }\end{array}$} & \multirow{4}{*}{$\begin{array}{c}\text { Between groups } \\
p\end{array}$} \\
\hline & \multicolumn{4}{|c|}{ Hospital group } & \multicolumn{4}{|c|}{ Home group } & \\
\hline & \multicolumn{2}{|c|}{ Baseline } & \multicolumn{2}{|c|}{ End } & \multicolumn{2}{|c|}{ Baseline } & \multicolumn{2}{|c|}{ End } & \\
\hline & Median & IQR & Median & IQR & Median & IQR & Median & IQR & \\
\hline \multirow[t]{2}{*}{ Total cholesterol } & 178 & $160-218$ & 144 & $138-168$ & 204 & $175-230$ & 169 & $150-178$ & $\mathrm{U}=44 ; \mathrm{p}=0.935$ \\
\hline & \multicolumn{2}{|c|}{$\mathrm{z}=2.497$} & \multicolumn{2}{|c|}{${ }^{*} \mathrm{p}=0.013$} & \multicolumn{2}{|c|}{$\mathrm{z}=2.192$} & \multicolumn{2}{|c|}{${ }^{*} \mathrm{p}=0.028$} & \\
\hline \multirow[t]{2}{*}{ Triglyceride } & 105 & $95-155$ & 100 & $92-150$ & 101 & $95-150$ & 100 & $92-150$ & $\mathrm{U}=41 ; \mathrm{p}=0.744$ \\
\hline & \multicolumn{2}{|c|}{$\mathrm{z}=1.122$} & \multicolumn{2}{|c|}{$\mathrm{p}=0.262$} & \multicolumn{2}{|c|}{$\mathrm{z}=1.140$} & \multicolumn{2}{|c|}{$\mathrm{p}=0.889$} & \\
\hline \multirow[t]{2}{*}{ HDL-C } & 22 & $20-25$ & 27 & $24-31$ & 25 & 20-30 & 30 & $25-40$ & $\mathrm{U}=33.5 ; \mathrm{p}=0.462$ \\
\hline & \multicolumn{2}{|c|}{$\mathrm{Z}=-2.803$} & \multicolumn{2}{|c|}{${ }^{*} \mathrm{p}=0.005$} & \multicolumn{2}{|c|}{$\mathrm{z}=-2.386$} & \multicolumn{2}{|c|}{${ }^{*} \mathrm{p}=0.017$} & \\
\hline \multirow[t]{2}{*}{ LDL-C } & 122 & $110-155$ & 107 & $95-130$ & 134 & $124-154$ & 114 & $100-128$ & $\mathrm{U}=36 ; \mathrm{p}=0.462$ \\
\hline & \multicolumn{2}{|c|}{$\mathrm{Z}=1.580$} & \multicolumn{2}{|c|}{$\mathrm{p}=0.114$} & \multicolumn{2}{|c|}{$\mathrm{z}=1.481$} & \multicolumn{2}{|c|}{$\mathrm{p}=0.139$} & \\
\hline
\end{tabular}


( $p>0.05)$ (Table 4). Total cholesterol levels decreased statistically significantly after CTE in both groups. In addition, high-density lipoprotein cholesterol (HDL-C) levels statistically significantly increased in both groups (Table 5).

There was no adverse event in any of the patients during the study. Drop-out rate was $1(10 \%)$ in the home-based CTE group who reported that he did not attend to at least four sessions (10\%) of the eightweek exercise program. The other patients in the home-based CTE group reported average two missed exercise sessions due to forgetting to do exercises $(n=8)$, family problems $(n=5)$, health problems $(n=3)$, upper respiratory tract infection $(n=3)$, or other reasons $(n=13)$. On the other hand, hospital-based CTE group participated in all the exercise sessions.

\section{DISCUSSION}

In this study, upper extremity muscle strength, $\mathrm{VO}_{2 \max }$, and maximum HR improved significantly in the groups after eight-week CTE program with elastic bands in males wheelchair users with paraplegia. Shoulder and elbow flexor-extensor peak torque values were improved significantly after CTE in both groups. There were no significant differences between the groups in terms of shoulder and elbow flexor-extensor peak torque. Yim et al. ${ }^{[17]}$ reported that there was a significant increase in the shoulder flexor peak torque values after five-week arm ergometer exercises in SCI patients. Moreover, no significant increase was reported in terms of the peak torque of the shoulder extensors, elbow extensors and flexors in the same study. A significant increase in the shoulder muscle strength was reported after an eight-week resistance training in a previous study. ${ }^{[18]}$ Inconsistent findings may result from the considerably different exercise designs that were used in studies. The CTE may help to increase upper extremity strength in patients with paraplegia. ${ }^{[9-13]}$ Yildirim et al. ${ }^{[13]}$ reported that upper extremity strengthening exercises using mechanical exercise stations combined with the conventional rehabilitation were useful in terms of increasing the strength and improving the physical disability as measured by the Functional Independence Measure in the persons with paraplegia. ${ }^{[13]}$

One of the main findings of the current study is the improvement in the $\mathrm{CV}$ endurance in both groups. The increase in the $\mathrm{VO}_{2 \max }$ was statistically higher in the supervised CTE group. The increase in $\mathrm{VO}_{2 \max }$ values were $44 \%$ and $28 \%$ for the supervised and home CTE groups, respectively. The increase in the $\mathrm{VO}_{2 \max }$ was reported between 7 and $99 \%$ in previous studies. ${ }^{[2,-9,17-22]}$ These wide differences are thought to be related to the heterogeneous patient populations. Working with elastic bands at home may help to improve both of the exercise capacity and the burn out time in SCI. ${ }^{[14]}$ Our findings are consistent with the previous studies. Yim et al. ${ }^{[17]}$ concluded that a wheelchair ergometer training for five weeks might help to decrease peak HR and blood pressure, besides the improvement in the strength of shoulder flexors in the patients with paraplegia.

Nash et al. ${ }^{[9]}$ reported that the circuit resistance training with elastic bands was as useful as the exercises on a multi-station isoinertial exercise station in terms of acute metabolic and chronotropic effects in patients with complete paraplegia. Keyser et al. ${ }^{[14]}$ reported that 12-week home program consisting of wheelchair propulsion such as exercises with elastic bands might help to improve cardiorespiratory endurance in the wheelchair users due to SCI or other disabilities. In a previous study, a significant increase in CV endurance was reported in which CTE was performed by using circuit hydraulic resistance exercises, three times a week for nine weeks in patients with paraplegia. ${ }^{[22]}$

In this study, there was a statistically significant increase in the HDL-C and a decrease in the total cholesterol levels after CTE in both groups. Furthermore, there was no significant difference in terms of these values between the groups. El Sayed and Younesian ${ }^{[8]}$ reported a statistically significant increase in HDL-C, but not in total cholesterol after exercises with an arm ergometer. They found that the minimum density was $70 \%$ for the benefits of exercise in terms of blood lipid levels. The results of this study are consistent to our study findings. In our study, the intensity of exercise was set as $70 \%$ of HR. Previous studies reported that exercise had a positive effect on lipid profile. ${ }^{[23,24]}$

In the present study, significant improvements were observed in terms of the physical independence and mobility domains as measured by CHART-SF in the supervised hospital CTE group; however, the improvements in the functional independence and mobility were not significant in the home-based CTE group. The increase in $\mathrm{VO}_{2 \max }$ and shoulder peak torque might be the factors related to the improvement in functional independence. Arm crank exercises provided no positive effect on functional status as measured by CHART-SF in the patients with paraplegia according to a previous study. ${ }^{[6]}$ Exercises may help to increase independence in SCI. ${ }^{[7,25,26]}$ Physical activity 
appears to have an important influence on social relationships, functional independence, psychological factors, and physical aspects, which can enhance quality of life and independence in the performance of daily activities. ${ }^{[26]}$

In our study, the dropout rate was $10 \%$ in the home CTE group. These results are in parallel with that of the previous studies. ${ }^{[17,21]}$ The reason for the low dropout rate in our study might be related to strict follow-up by regular phone calls. In general, upper extremity exercises are well tolerated by the patients with SCI. ${ }^{[8,17-20]}$

This study has some limitations. One of the limitations of our study is the relatively small sample size. The second one is that the study included only male patients with paraplegia and, therefore, the results cannot be generalized to all patients with SCI.

In conclusion, upper extremity strength, CV endurance, and blood lipid profile were all improved significantly after an eight-week CTE in male patients with paraplegia. There was a significant increase in the physical independence and mobility only in the supervised exercise group. Based on these results, home-based programs may be good alternatives to the hospital rehabilitation which is associated with high cost burden and transportation issues.

\section{Declaration of conflicting interests}

The authors declared no conflicts of interest with respect to the authorship and/or publication of this article.

\section{Funding}

This study was funded by Istanbul University with the project number T 640/17032005.

\section{REFERENCES}

1. Ferri-Caruana A, Millán-González L, García-Massó $X$, Pérez-Nombela S, Pellicer-Chenoll M, Serra-Añó P. Accelerometer assessment of physical activity in individuals with paraplegia who do and do not participate in physical exercise. J Spinal Cord Med 2020;43:234-40.

2. Grange CC, Bougenot MP, Groslambert A, Tordi N, Rouillon JD. Perceived exertion and rehabilitation with wheelchair ergometer: Comparison between patients with spinal cord injury and healthy subjects. Spinal Cord 2002;40:513-8.

3. Haisma JA, Bussmann JB, Stam HJ, Sluis TA, Bergen MP, Dallmeijer AJ, et al. Changes in physical capacity during and after inpatient rehabilitation in subjects with a spinal cord injury. Arch Phys Med Rehabil 2006;87:741-8.

4. Sipski ML, Richards JS. Spinal cord injury rehabilitation: State of the science. Am J Phys Med Rehabil 2006;85:310-42.

5. Chiodo AE, Scelza WM, Kirshblum SC, Wuermser LA, Ho $\mathrm{CH}$, Priebe MM. Spinal cord injury medicine. 5. Long-term medical issues and health maintenance. Arch Phys Med Rehabil 2007;88(3 Suppl 1):S76-83.
6. Akkurt H, Karapolat HU, Kirazli Y, Kose T. The effects of upper extremity aerobic exercise in patients with spinal cord injury: A randomized controlled study. Eur J Phys Rehabil Med 2017;53:219-27.

7. Bochkezanian V, Raymond J, de Oliveira CQ, Davis GM. Can combined aerobic and muscle strength training improve aerobic fitness, muscle strength, function and quality of life in people with spinal cord injury? A systematic review. Spinal Cord 2015;53:418-31.

8. El-Sayed MS, Younesian A. Lipid profiles are influenced by arm cranking exercise and training in individuals with spinal cord injury. Spinal Cord 2005;43:299-305.

9. Nash MS, Jacobs PL, Woods JM, Clark JE, PrayTA, Pumarejo AE. A comparison of 2 circuit exercise training techniques for eliciting matched metabolic responses in persons with paraplegia. Arch Phys Med Rehabil 2002;83:201-9.

10. Jacobs PL, Nash MS, Rusinowski JW. Circuit training provides cardiorespiratory and strength benefits in persons with paraplegia. Med Sci Sports Exerc 2001;33:711-7.

11. Sasso E, Backus D. Home-based circuit resistance training to overcome barriers to exercise for people with spinal cord injury: A case study. J Neurol Phys Ther 2013;37:65-71.

12. Nash MS, van de Ven I, van Elk N, Johnson BM. Effects of circuit resistance training on fitness attributes and upperextremity pain in middle-aged men with paraplegia. Arch Phys Med Rehabil 2007;88:70-5.

13. Yildirim A, Sürücü GD, Karamercan A, Gedik DE, Atci N, Dülgeroğlu D, et al. Short-term effects of upper extremity circuit resistance training on muscle strength and functional independence in patients with paraplegia. J Back Musculoskelet Rehabil 2016;29:817-23.

14. Keyser RE, Rasch EK, Finley M, Rodgers MM. Improved upper-body endurance following a 12-week home exercise program for manual wheelchair users. J Rehabil Res Dev 2003;40:501-10.

15. Whiteneck GG, Charlifue SW, Gerhart KA, Overholser JD, Richardson GN. Quantifying handicap: A new measure of long-term rehabilitation outcomes. Arch Phys Med Rehabil 1992;73:519-26.

16. Kesiktas N, Yavuzer G, Cakmak A, Issever H, Muslumanoglu L. Clinometric properties of turkish version of Craig handicap assessment and reporting technique short form. J Spinal Cord Med 2006;29:299-300.

17. Yim SY, Cho KJ, Park CI, Yoon TS, Han DY, Kim SK, et al. Effect of wheelchair ergometer training on spinal cordinjured paraplegics. Yonsei Med J 1993;34:278-86.

18. Serra-Añó P, Pellicer-Chenoll M, García-Massó X, Morales J, Giner-Pascual M, González LM. Effects of resistance training on strength, pain and shoulder functionality in paraplegics. Spinal Cord 2012;50:827-31.

19. Bougenot MP, Tordi N, Betik AC, Martin X, Le Foll D, Parratte B, et al. Effects of a wheelchair ergometer training programme on spinal cord-injured persons. Spinal Cord 2003;41:451-6.

20. Tordi N, Dugue B, Klupzinski D, Rasseneur L, Rouillon JD, Lonsdorfer J. Interval training program on a wheelchair ergometer for paraplegic subjects. Spinal Cord 2001;39:532-7. 
21. Sutbeyaz ST, Koseoglu BF, Gokkaya NK. The combined effects of controlled breathing techniques and ventilatory and upper extremity muscle exercise on cardiopulmonary responses in patients with spinal cord injury. Int J Rehabil Res 2005;28:273-6.

22. Cooney MM, Walker JB. Hydraulic resistance exercise benefits cardiovascular fitness of spinal cord injured. Med Sci Sports Exerc 1986;18:522-5.

23. de Groot PC, Hjeltnes N, Heijboer AC, Stal W, Birkeland K. Effect of training intensity on physical capacity, lipid profile and insulin sensitivity in early rehabilitation of spinal cord injured individuals. Spinal Cord 2003;41:673-9.

24. Liusuwan RA, Widman LM, Abresch RT, Johnson AJ,
McDonald CM. Behavioral intervention, exercise, and nutrition education to improve health and fitness (BENEfit) in adolescents with mobility impairment due to spinal cord dysfunction. J Spinal Cord Med 2007;30 Suppl 1:S119-26.

25. Rahimi M, Torkaman G, Ghabaee M, Ghasem-Zadeh A. Advanced weight-bearing mat exercises combined with functional electrical stimulation to improve the ability of wheelchair-dependent people with spinal cord injury to transfer and attain independence in activities of daily living: A randomized controlled trial. Spinal Cord 2020;58:78-85.

26. Kawanishi CY, Greguol M. Physical activity, quality of life, and functional autonomy of adults with spinal cord injuries. Adapt Phys Activ Q 2013;30:317-37. 